\title{
Measuring Brain Tissue Integrity during 4 Years Using Diffusion Tensor Imaging
}

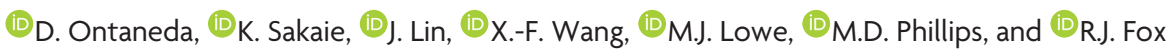

\begin{abstract}
BACKGROUND AND PURPOSE: DTI is an MR imaging measure of brain tissue integrity. Little is known regarding the long-term longitudinal evolution of lesional and nonlesional tissue DTI parameters in multiple sclerosis and the present study examines DTI evolution over 4 years.
\end{abstract}

MATERIALS AND METHODS: Twenty-one patients with multiple sclerosis were imaged for up to 48 months after starting natalizumab therapy. Gadolinium-enhancing lesions at baseline, chronic T2 lesions, and normal-appearing white matter were followed longitudinally. T2 lesions were subclassified as black holes and non-black holes. Within each ROI, the average values of DTI metrics were derived by using Analysis of Functional Neuro Images software. The longitudinal trend in DTI metrics was estimated by using a mixed-model regression analysis.

RESULTS: A significant increase was observed for axial diffusivity $(P<.001)$ in gadolinium-enhancing lesions and chronic T2 lesions during 4 years. No significant change in radial diffusivity either in normal-appearing white matter or lesional tissue was observed. The evolution of axial diffusivity was different in gadolinium-enhancing lesions $(P<.001)$ and chronic T2 lesions $(P=.02)$ compared with normalappearing white matter.

CONCLUSIONS: An increase in axial diffusion in both gadolinium-enhancing lesions and T2 lesions may relate to the complex evolution of chronically demyelinated brain tissue. Pathologic changes in normal-appearing white matter are likely more subtle than in lesional tissue and may explain the stability of these measures with DTI.

ABBREVIATIONS: $\mathrm{AD}=$ axial diffusivity; $\mathrm{BH}=$ black hole(s); $\mathrm{FA}=$ fractional anisotropy; $\mathrm{GAD}=$ gadolinium-enhancing lesion; $\mathrm{MD}=$ mean diffusivity; $\mathrm{NAWM}=$ normal-appearing white matter; $\mathrm{NBH}=$ non-black hole(s); $\mathrm{RD}=$ radial diffusivity

$\mathbf{M}_{\mathrm{i}}^{\mathrm{s}}$ $S$ is the leading nontraumatic cause of neurologic disability in young adults in North America. MS pathology is characterized by focal inflammatory demyelinating lesions and diffuse changes in myelin, axon, and neuronal components. ${ }^{1}$ Conventional MR imaging in MS has limitations because this technique provides little insight into the underlying pathology of MS lesions, is not sensitive enough to detect tissue changes outside lesions (ie, normal-appearing white matter [NAWM]), and is unable to quantify pathologic substrates of disease such as myelin or axonal

Received May 10, 2016; accepted after revision July 26.

From the Department of Neurology (D.O., R.J.F.), Neurological Institute, Mellen Center for Multiple Sclerosis Treatment and Research; Imaging Institute (K.S., J.L. M.J.L., M.D.P.); and Department of Quantitative Health Sciences (X.-F.W.), Cleveland Clinic Foundation, Cleveland, Ohio.

This work was funded by National Institutes of Health grant KL2 TR000440 to D. Ontaneda and National Multiple Sclerosis Society grants, FP1769-A-1 to D. Ontaneda and RG3548 to R.J. Fox.

Please address correspondence to Daniel Ontaneda, MD, Mellen Center for Multiple Sclerosis Treatment and Research, Cleveland Clinic Foundation, 9500 Euclid Ave, U-10, Cleveland, OH 44195; e-mail: ontaned@ccf.org; @dxo60_daniel

- Indicates open access to non-subscribers at www.ajnr.org

http://dx.doi.org/10.3174/ajnr.A4946 content. Additionally, conventional MR imaging is a relatively insensitive technique in progressive forms of MS in which there is little overt inflammatory activity, and MR imaging-detected lesion burden often does not change despite frequent clear-cut clinical progression. ${ }^{2}$

DTI is a quantitative MR imaging-based technique that measures the diffusion of water in brain tissue. ${ }^{3}$ The diffusion properties are thought to reflect the microstructure of the underlying tissue. ${ }^{4}$ DTI metrics include the following: mean diffusivity (MD), fractional anisotropy (FA), radial diffusivity (RD), and axial diffusivity $(\mathrm{AD})$. The different DTI metrics carry a pathologic specificity as well. AD is correlated pathologically with axonal loss in animal models of retinal ischemia. ${ }^{5} \mathrm{RD}$ is thought to be a measure of myelin content based on studies examining animal models of demyelination. ${ }^{6}$ DTI may provide a window into the pathologic processes in MS, and through serial imaging studies, it can be used to follow MS lesions in different stages and tissue changes with time. ${ }^{7}$ Additionally, DTI has demonstrated the ability to detect changes in brain tissue that is apparently free of lesions (normal-appearing brain tissue) under standard MR imaging. ${ }^{8}$

Longitudinal studies examining DTI characteristics have typ- 
ically only been conducted for 1-2 years with a smaller number of diffusion directions than with currently available high-angularresolution diffusion imaging. Harrison et $\mathrm{al}^{8}$ studied the evolution of white matter tracts based on tractography and found that there was a significant increase in FA and a decrease in RD during a 2-year follow-up period, with most patients in that study being on disease-modifying treatment. Lesional tissue has been studied in acute phases or for short periods of follow-up (1-2 years), and it most consistently has shown increases in MD and RD with a decrease in FA. ${ }^{9-12}$ Diffusion imaging studies have also shown that T1 black holes have higher levels of diffusivity compared with isointense T1 lesions. ${ }^{13}$ There is evidence that radial diffusivity is a strong predictor of T1 black hole conversion. ${ }^{11}$ Alternatively, longitudinal studies of high-angular-resolution diffusion imaging following lesion evolution with time have not been conducted, to our knowledge.

Natalizumab is a monoclonal antibody directed at the very late antigen-4 receptor on leukocytes. ${ }^{14}$ Most patients treated with natalizumab enter a relatively inflammation-free state, which enables the study of the underlying neurodegenerative and reparative aspects of MS, similar to those seen in progressive MS. DTI is a feasible alternative to measure underlying neurodegeneration and to assess the efficacy of potential neuroprotectant medications.

In this study, we aimed to study the evolution of lesional and nonlesional tissue in patients treated with natalizumab during a 4-year period. Previous DTI studies have used low angular resolution and have followed patients for only up to 2 years. ${ }^{8}$ The high-angular-resolution diffusion imaging acquisition ${ }^{15}$ reduces the variability and bias found in lower-angular-resolution approaches, allows a more accurate study of DTI metrics with time, and shows advantages over using a small number of diffusion directions. ${ }^{16}$

\section{MATERIALS AND METHODS Participants}

Twenty-two patients with relapsing MS starting natalizumab therapy were sequentially enrolled from neurologist referrals at an academic specialty clinical center in an institutional review board-approved longitudinal observational imaging study, as previously described. ${ }^{17}$ Inclusion criteria were clinically definite MS by the 2005 Revised McDonald Criteria, ${ }^{18}$ age older than 18 years, and the ability to provide informed consent. Exclusion criteria were clinical relapse or steroid treatment in the previous 8 weeks, pregnancy, and contraindications to MR imaging such as severe claustrophobia and implanted devices such as neurostimulators and pacemakers. One patient discontinued imaging follow-up after only 2 months and was removed from the data analysis.

\section{MR Imaging Protocol}

MR imaging of the brain was serially performed at time baseline (before natalizumab dosing) and at 1, 2, 6, 12, 18, 24, 36, and 48 months. Images were obtained on a $3 \mathrm{~T}$ Magnetom Trio scanner (Siemens, Erlangen, Germany). Diffusion-weighted imaging used 71 noncollinear diffusion-weighting gradients $(2.5 \times 2.5 \times 2.5$ mm voxels, $b=1000 \mathrm{~s} / \mathrm{mm}^{2}, 8 b=0$ acquisitions, $260 \times 260 \mathrm{~mm}$ FOV, $104 \times 104$ matrix, forty-eight $2.5-\mathrm{mm}$ sections, $\mathrm{TE}=95 \mathrm{~ms}$, $\mathrm{TR}=7300 \mathrm{~ms}$ ). The b-value of the DTI sequence was reduced at
12 months from $b=2000 \mathrm{~s} / \mathrm{mm}^{2}$ to $b=1000 \mathrm{~s} / \mathrm{mm}^{2}$. This change was implemented to address vibration-related artifacts observed at the higher b-value. ${ }^{19}$ Anatomic imaging was performed for lesion detection and coregistration: 3D MPRAGE $(256 \times 256 \mathrm{~mm}$ FOV, $128 \times 256$ matrix, one hundred twenty $1.2-\mathrm{mm}$ sections, $\mathrm{TE}=1.71 \mathrm{~ms}, \mathrm{TR}=1900 \mathrm{~ms}, \mathrm{~T} 1=900 \mathrm{~ms}$, flip angle $\left.=8^{\circ}\right) ;$ proton density/T2-weighted $(230 \times 230 \mathrm{~mm}$ FOV, $320 \times 320$ matrix, forty-eight $3-\mathrm{mm}$ sections, $\mathrm{TE}_{1}=20 \mathrm{~ms}, \mathrm{TE}_{2}=91 \mathrm{~ms}$, $\mathrm{TR}=3600 \mathrm{~ms}) ;$ and $\mathrm{T} 1$ postgadolinium sequences $(230 \times 230$ $\mathrm{mm}$ FOV, $320 \times 320$ matrix, forty-eight $3-\mathrm{mm}$ sections, $\mathrm{TE}=$ $2.46 \mathrm{~ms}$, TR $300 \mathrm{~ms}$, flip angle $=75^{\circ}$ ).

\section{Image Analysis}

For each subject, ROIs were manually drawn (authors: D.O. and R.J.F.) using Analysis of Functional Neuro Images software (AFNI; http://afni.nimh.nih.gov/afni) on all areas with pathologic gadolinium enhancement on $\mathrm{T} 1$ postcontrast images at the baseline scan and will be referred to as GAD tissue. Ten ROIs were sequentially drawn in selected chronic lesional tissue (T2 lesions and T1 black holes) also on the baseline scan, and these included 2 lesions in the following locations: periventricular, juxtacortical, corpus callosum, infratentorial, and posterior periatrial (Fig 1). If subjects did not have lesions in the prespecified regions with the required T1/T2 signal characteristics, these regions were ignored. T2 lesions were labeled as black hole $(\mathrm{BH})$ and non-black hole $(\mathrm{NBH})$. T1 black holes were differentiated from $\mathrm{NBH}$ by a visible decrease in signal intensity on the $\mathrm{T} 1$ sequence compared with normal-appearing adjacent white matter tissue, as has been described previously. ${ }^{20}$

Images from each time point were coregistered by using the FMRIB Software Library (FSL; http://fsl.fmrib.ox.ac.uk/). ${ }^{21}$ The images from the DTI dataset without diffusion weighting, the $b=0$ images, were coregistered to the baseline T1-weighted images to determine tensor properties in lesional tissues. Inverse transformation was applied to localize ROIs in DTI space. GAD ROIs were observed on FA maps to ensure that these ROIs did not include CSF or CSF volume-averaging artifacts. Lesional ROIs were examined on FA maps and $\mathrm{T} 1$ postcontrast images to ensure that ROIs did not include T1 GAD lesions, CSF, or CSF volumeaveraging artifacts. FA was used, given the possibility of image warping in DTI space to ensure that ROIs were not in the CSF or voxels adjacent to the CSF.

For each subject, 16 ROIs were also drawn in the normalappearing white matter bilaterally. These included 2 ROIs (ipsilateral and contralateral) in each of the following regions: corticospinal tracts in the pons, corticospinal tract in the midbrain, anterior limb of the internal capsule, posterior limb of the internal capsule, anterior corpus callosum, posterior corpus callosum, centrum semiovale, and deep white matter of the frontal lobe (Fig 1). ROIs were drawn individually on the coregistered FA maps at each time point with simultaneous observation of the T2 and T1 postcontrast scans to ensure that ROIs did not include T2 lesions, T1 gadolinium-enhancing lesions, CSF, or CSF volume-averaging artifacts and voxels adjacent to CSF. Lesions were shifted within the tract when possible to avoid the above changes, but when this was not possible, these ROIs were eliminated from the analysis. 


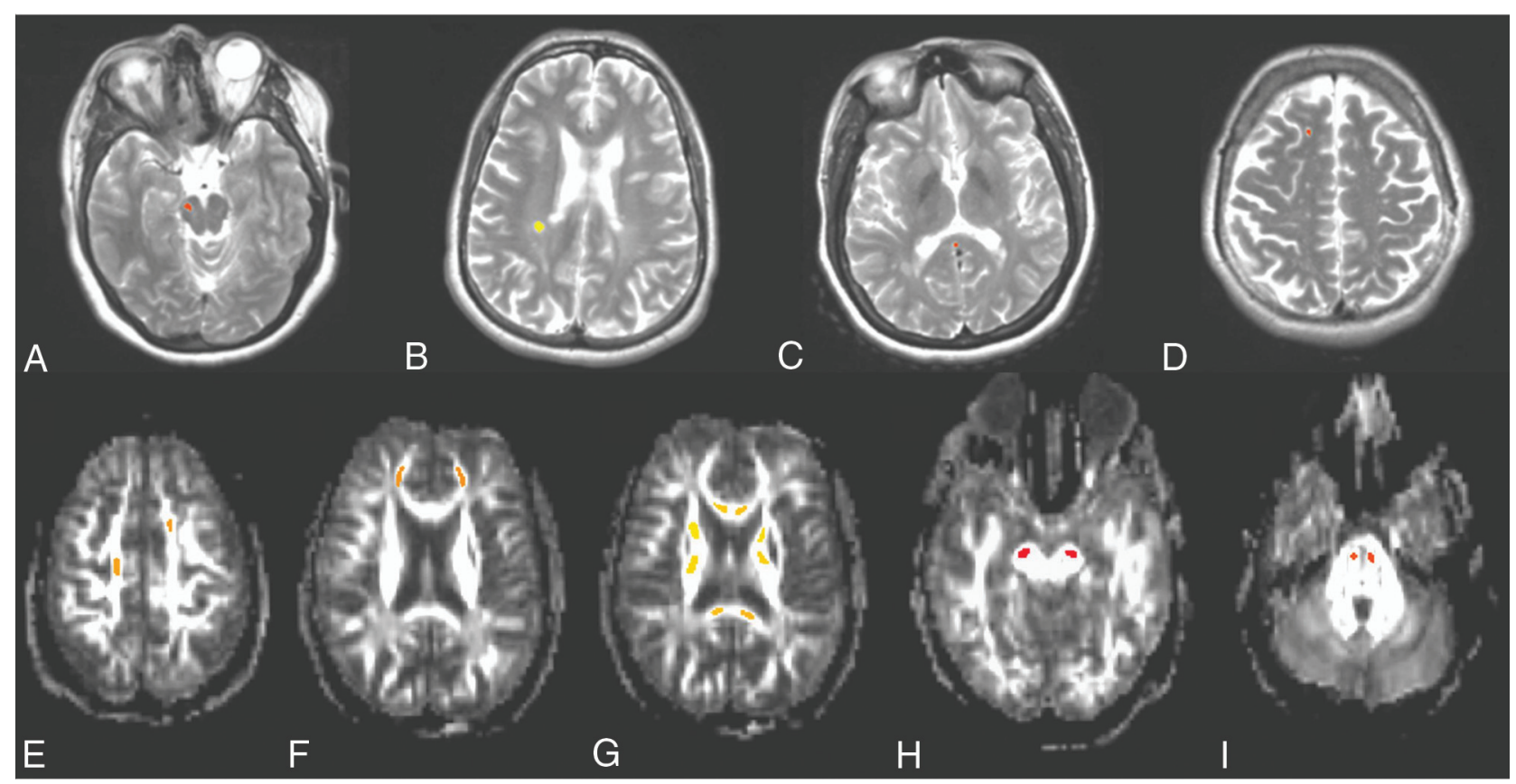

FIG 1. ROIs in infratentorial $(A)$, posterior periatrial $(B)$, corpus callosum $(C)$, and juxtacortical $(D)$ lesional tissues on postcontrast T2-weighted images. Note ROls in normal-appearing white matter locations $(E-I)$ on fractional anisotropy maps.

\section{Statistical Analysis}

The data from each ROI from the FA, MD, RD, and AD maps at all the different time points were extracted. For each subject, distribution plots of the data were created to identify extreme outliers ( $>2$ SDs from the mean). ROI positions of outliers were checked on the different DTI maps and were corrected as needed to ensure that the ROIs did not include CSF, vascular spaces, or lesional tissue (for NAWM). The data were then re-extracted and rechecked.

Statistical testing was directed at demonstrating longitudinal change in DTI metrics among the different tissue types. Hypothesis-driven separate linear mixed models were used to estimate the mean difference in DTI metrics ( $R D, A D, F A$, and $M D)$ with time between NAWM and GAD tissue, NAWM versus T2 lesions, and $\mathrm{BH}$ versus $\mathrm{NBH}$. We hypothesized that NAWM would be more stable compared with $\mathrm{GAD}$ and that $\mathrm{BH}$ would demonstrate more tissue injury than NBH. Each model included fixed effects for the following: 1) tissue type (NAWM and GAD tissue, NAWM and $\mathrm{T} 2$ lesions, or $\mathrm{BH}$ and $\mathrm{NBH}$ ), 2) an interaction between tissue type and follow-up time in months (to separately model the DTI evolution in each group with time), and 3) subject age at the time of study initiation (to account for the change observed in DTI metrics with normal aging with time). The model also accounted for the effects of between-lesion variation with time by adding a normal random effect for each ROI to control the heterogeneity over different ROIs. ANOVA tests were used to determine whether the rate of change in DTI measures with time differed between tissue types. All analyses were performed by using the $\mathrm{R}$ Statistical Computing Software (Version 3.1.3; http://www.rproject.org/). The level of statistical significance was set at $P<$ .025 (2-tailed) with a correction for multiple comparisons, to adjust for the 2 independent DTI metrics used in the study (RD, $\mathrm{AD})$. A formal sample size calculation was not conducted, given the exploratory nature of the study.

\section{RESULTS}

Twenty-one subjects were recruited into the study. Demographics and baseline clinical/MR imaging characteristics have been previously published in the American Journal of Neuroradiology. ${ }^{17} \mathrm{Sev}$ enteen $(81.0 \%)$ subjects completed the 48 -month scan, 1 subject died due to an unrelated cardiac event, and 3 subjects withdrew from the study before completion (at 12, 18, and 24 months). Figure 2 shows AD and RD boxplots for NAWM, GAD, and T2 lesions. Sixty-one GADs were identified at baseline (mean lesion size, $751.3 \mathrm{~mm}^{3}$ ) along with 141 chronic T2 lesions, of which 90 were $\mathrm{BH}$ and 51 were $\mathrm{NBH}$ (mean T2 lesion size, $666.8 \mathrm{~mm}^{3}$ ).

Longitudinal DTI metrics for NAWM, GAD, and T2 lesions are presented in Fig 3. Results of linear mixed-effects models with average yearly changes in DTI metrics are presented in Tables 1 (NAWM, GAD) and 2 (T2 lesions).

\section{DTI Changes in NAWM}

No statistically significant changes were observed with time in DTI metrics from NAWM ROIs (all $P>.08$ ). RD and MD showed an increasing trend with time, while FA and $\mathrm{AD}$ showed a trend toward decreases with time.

\section{DTI Changes in GAD}

An increase in $\mathrm{AD}$ of $1.88 \times 10^{-6} \mathrm{~mm}^{2} / \mathrm{s}$ per month was observed during 4 years in GAD tissues $(P<.0001)$. A nonsignificant increase of $0.66 \times 10^{-6} \mathrm{~mm}^{2} / \mathrm{s}$ change per month in RD was observed $(P=.037)$, which, in combination with $\mathrm{AD}$, resulted in an overall increase of $1.28 \times 10^{-6} \mathrm{~mm}^{2} / \mathrm{s}$ per month $(P<.0001)$ in $\mathrm{MD}$ as well.

\section{DTI Changes in $T 2$ Lesions}

$\mathrm{RD}$ did not significantly change with time in T2 lesions. An increase of $0.54 \times 10^{-6} \mathrm{~mm}^{2} / \mathrm{s}$ per month in $\operatorname{AD}(P=.003)$ with a concomitant increase in MD of $0.27 \times 10^{-6} \mathrm{~mm}^{2} / \mathrm{s}$ per month 

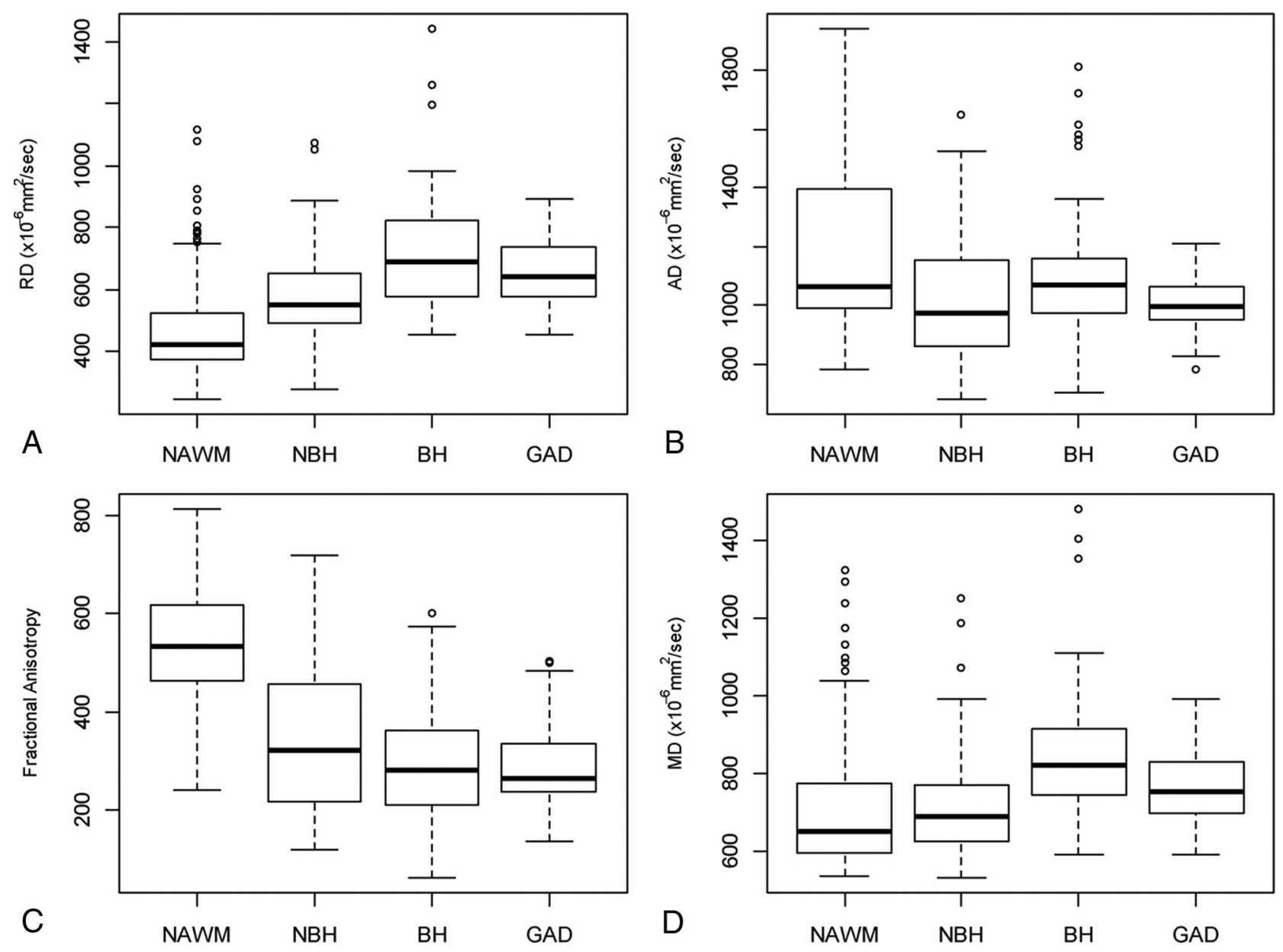

FIG 2. Baseline DTI characteristics of normal-appearing white matter, non-black holes, black holes, and gadolinium-enhancing lesions for radial diffusivity $(A)$, axial diffusivity $(B)$, fractional anisotropy $(C)$, and mean diffusivity $(D)$. Boxplots show median (dark line), upper and lower quartiles (box), maximum and minimum values excluding outliers (whiskers), and outliers (circles).

$(P=.021)$ was observed. FA increased by $0.16 \times 10^{-6} \mathrm{~mm}^{2} / \mathrm{s}$ per month, but this increase was not statistically significant $(P=$ .048). No significant changes were seen in the evolution of DTI metrics in either $\mathrm{BH}$ or NBH when analyzed alone (all $P>.04$ ). $\mathrm{RD}$ increased with time in $\mathrm{BH}$ and decreased in $\mathrm{NBH}$, though changes were not significant.

\section{Comparative Evolution of DTI in Different Tissue Types}

The tests of fixed effects by ANOVA (Table 3) showed a significant difference between GAD and NAWM in the rate of change with time in $\mathrm{AD}(P<.0001)$, but not for $\mathrm{RD}(P=.111)$. AD increased with time in GAD tissue and was stable in NAWM. When we compared T2 lesions and NAWM, a significant difference was detected for $\operatorname{AD}(P=.002)$, with no significant difference for RD $(P=.86)$. When we compared $\mathrm{BH}$ and $\mathrm{NBH}$, no differences were observed for $\mathrm{RD}$ or $\mathrm{AD}$; however, a significant difference in the evolution of FA was observed between $\mathrm{BH}$ and $\mathrm{NBH}(P=.012)$, showing a decrease in $\mathrm{FA}$ in $\mathrm{BH}$ and an increase in $\mathrm{NBH}$.

\section{DISCUSSION}

At baseline, DTI metrics showed expected differences, with higher $\mathrm{RD}$ and $\mathrm{MD}$ along with lower FA and $\mathrm{AD}$ in gadolinium-enhancing tissue compared with NAWM. This finding suggests the presence of more severe demyelination and axon loss in lesional tissue compared with NAWM based on the findings in animal models, showing that $\mathrm{RD}$ correlates with myelination and $\mathrm{AD}$ correlates with axonal injury. ${ }^{6,22}$ It is likely that edema was an additional contributing factor to an increase in RD at the time of acute demyelination. ${ }^{23}$ In chronic T2 lesions, DTI metrics at baseline showed higher RD and MD with lower FA and AD compared with NAWM. DTI metrics at baseline were similar in GAD and chronic T2 lesions, but overall GAD tissues had slightly higher RD and slightly lower FA, MD, and $\mathrm{AD}$ at baseline. Similar to prior studies, ${ }^{24,25} \mathrm{BH}$ showed greater diffusivity at baseline compared with $\mathrm{NBH}$, suggesting greater tissue injury. As would be expected, FA was significantly lower at baseline in $\mathrm{BH}$ than in NBH. Alternatively, $\mathrm{AD}$ at baseline was similar in $\mathrm{BH}$ and $\mathrm{NBH}$. This outcome would not normally be expected because axon loss is a clear histologic feature of $\mathrm{BH}$ lesions. ${ }^{26,27}$ Our findings illustrate why equating $\mathrm{AD}$ with axonal integrity is an oversimplification of a complex measure. Our findings are similar to previous results showing that $\mathrm{AD}$ does not predict $\mathrm{BH}$ formation. ${ }^{11,17}$

No statistically significant changes were observed in the longitudinal evolution of DTI metrics in NAWM. This finding is consistent with the findings of previous groups, ${ }^{28}$ but it is in contrast to previous shorter term studies that have shown tract-specific longitudinal changes in NAWM DTI values. ${ }^{8}$ The trends observed 

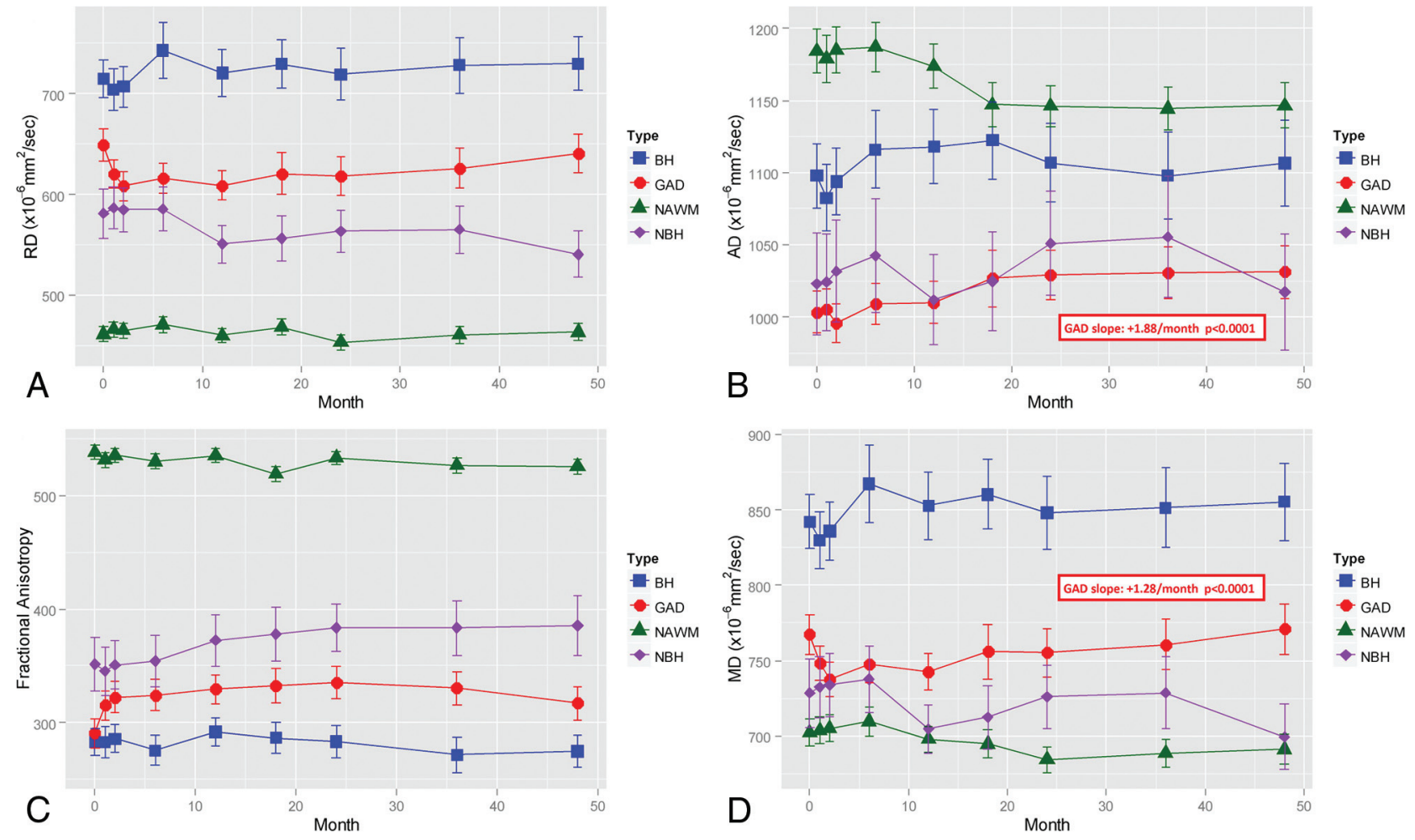

FIG 3. Longitudinal evolution of DTI metrics during 4 years for, non-black holes, black holes, and gadolinium-enhancing lesions for radial diffusivity $(A)$, axial diffusivity $(B)$, fractional anisotropy $(C)$, and mean diffusivity $(D)$. Mean values (symbol) and $95 \%$ confidence intervals (error bars) are presented. Statistical significance and effect from the mixed-model effect are presented in boxes.

Table 1: Longitudinal DTI changes in NAWM and GAD

\begin{tabular}{lcccc}
\hline & $\begin{array}{c}\text { Change/ } \\
\text { Month }\end{array}$ & $95 \% \mathrm{Cl}$ & $\begin{array}{c}\text { \% Annualized } \\
\text { Change }\end{array}$ & P Value \\
\hline NAWM & & & & \\
$\mathrm{RD} \times 10^{-6} \mathrm{~mm}^{2} / \mathrm{s}$ & 0.2193 & -0.187 to 0.625 & $0.57 \%$ & .2898 \\
$\mathrm{AD} \times 10^{-6} \mathrm{~mm}^{2} / \mathrm{s}$ & -0.2109 & -0.614 to 0.192 & $-0.21 \%$ & .3052 \\
$\mathrm{FA} \times 10^{-3}$ & -0.2572 & -0.551 to 0.037 & $-0.57 \%$ & .0865 \\
$\mathrm{MD} \times 10^{-6} \mathrm{~mm}^{2} / \mathrm{s}$ & 0.03209 & -0.331 to 0.396 & $0.05 \%$ & .8626 \\
$\mathrm{GAD}$ & & & & \\
$\mathrm{RD} \times 10^{-6} \mathrm{~mm}^{2} / \mathrm{s}$ & 0.6107 & 0.039 to 1.285 & $1.22 \%$ & .0374 \\
$\mathrm{AD} \times 10^{-6} \mathrm{~mm}^{2} / \mathrm{s}$ & 1.8831 & 1.135 to 2.631 & $2.25 \%$ & $<.0001^{\text {a }}$ \\
$\mathrm{FA} \times 10^{-3}$ & 0.5074 & 0.031 to 0.984 & $2.10 \%$ & .037 \\
$\mathrm{MD} \times 10^{-6} \mathrm{~mm}^{2} / \mathrm{s}$ & 1.2788 & 0.695 to 1.863 & $2.00 \%$ & $<.001^{\text {a }}$ \\
\hline${ }^{a} P<.05$. & & &
\end{tabular}

in NAWM changes with time in our study were similar to what would be pathophysiologically expected, with an increase in RD and decrease in $\mathrm{AD}$ with time indicating progressive demyelination with ongoing axonal loss. One explanation for the absence of statistical significance is the relative lack of inflammatory activity seen in our patient population. Highly effective treatment may mitigate longitudinal changes in DTI. Anti-inflammatory therapies are likely to limit the amount of demyelination and secondary axon loss, making differences more difficult to observe. ${ }^{29}$ A second explanation may relate to technical differences between our study and that of Harrison et al. ${ }^{8}$ In our study, ROIs in the NAWM were individually drawn and voxel volume was relatively small compared with a tractography-based technique. A larger sample size of voxels may have shown statistically significant results in the trends described above.

In gadolinium-enhancing tissue, significant changes were ob- served in $\mathrm{AD}$ and $\mathrm{MD}$ during the study period. A progressive increase in $\mathrm{AD}$ was observed during 4 years and is similar to prior findings. Naismith et $\mathrm{al}^{11}$ did not find significant changes in $\mathrm{AD}$ at the time of gadolinium-enhancement, but in their data, $\mathrm{AD}$ also appeared to increase during 1 year of follow-up. The longitudinal increase in $\mathrm{AD}$ may have been partially driven by the increase in $\mathrm{AD}$ observed in the first month following lesion formation; however, inspection of the trend of $\mathrm{AD}$ shows that this was only a marginal contribution. Given similar results observed in T2 lesions (see below), we conclude that the change in $\mathrm{AD}$ is likely a biologic effect in lesional tissue. An alternate explanation may relate to the severity of axon loss in acute lesions. Postmortem analyses have shown that axon loss is maximal at the time of gadolinium-enhancement and that with time, axonal loss becomes less prevalent. ${ }^{30}$ It is hypothesized that the initial injury causes an acute and severe loss of axons, which is detected by a marked drop in $\mathrm{AD}$. The subsequent increase in $\mathrm{AD}$ might be a reflection of a secondary process occurring during chronic lesion evolution. The increase in $\mathrm{AD}$ may be due to a partial repair mechanism or may represent chronic lesion changes with scar formation or replacement by CSF/glial tissue.

When comparing the longitudinal evolution of DTI in GAD tissue and NAWM, significant differences were found for AD but not $\mathrm{RD}$. This finding may indicate that distinct processes 
Table 2: Longitudinal DTI changes in chronic lesional tissue

\begin{tabular}{lcccl}
\hline & Change/Month & $95 \% \mathrm{Cl}$ & $\begin{array}{c}\text { \% Annualized } \\
\text { Change }\end{array}$ & $\boldsymbol{P}$ Value \\
\hline All T2 lesions & & & & \\
$\mathrm{RD} \times 10^{-6} \mathrm{~mm}^{2} / \mathrm{s}$ & 0.05683 & -0.181 to 0.295 & $0.11 \%$ & .6401 \\
$\mathrm{AD} \times 10^{-6} \mathrm{~mm}^{2} / \mathrm{s}$ & 0.5411 & 0.251 to 0.831 & $0.62 \%$ & $.0003^{\text {a }}$ \\
$\mathrm{FA} \times 10^{-3}$ & 0.163 & 0.001 to 0.324 & $0.61 \%$ & $.0482^{\mathrm{a}}$ \\
$\mathrm{MD} \times 10^{-6} \mathrm{~mm}^{2} / \mathrm{s}$ & 0.2695 & 0.040 to 0.499 & $0.41 \%$ & $.0211^{\mathrm{a}}$ \\
$\mathrm{BH}$ & & & & \\
$\mathrm{RD} \times 10^{-6} \mathrm{~mm}^{2} / \mathrm{s}$ & 0.3392 & -0.028 to 0.706 & $0.57 \%$ & .0701 \\
$\mathrm{AD} \times 10^{-6} \mathrm{~mm}^{2} / \mathrm{s}$ & 0.1967 & -0.200 to 0.593 & $0.22 \%$ & .331 \\
$\mathrm{FA} \times 10^{-3}$ & -0.2137 & -0.422 to -0.005 & $-0.91 \%$ & .0444 \\
$\mathrm{MD} \times 10^{-6} \mathrm{~mm}^{2} / \mathrm{s}$ & 0.2919 & -0.059 to 0.643 & $0.42 \%$ & .1026 \\
$\mathrm{NBH}$ & & & & \\
$\mathrm{RD} \times 10^{-6} \mathrm{~mm}^{2} / \mathrm{s}$ & -0.4137 & -0.967 to 0.140 & $-0.85 \%$ & .1432 \\
$\mathrm{AD} \times 10^{-6} \mathrm{~mm}^{2} / \mathrm{s}$ & -0.2392 & -0.838 to 0.360 & $-0.28 \%$ & .434 \\
$\mathrm{FA} \times 10^{-3}$ & 0.2907 & -0.025 to 0.606 & $0.99 \%$ & .0708 \\
$\mathrm{MD} \times 10^{-6} \mathrm{~mm}^{2} / \mathrm{s}$ & -0.355 & -0.174 to 0.884 & $-0.58 \%$ & .1883 \\
\hline
\end{tabular}

a $p<.05$.

\begin{tabular}{lc}
$\begin{array}{l}\text { Table 3: Analysis of variance of fixed effects on longitudinal } \\
\text { changes comparing evolution of DTI metrics from different } \\
\text { tissue types during } 4 \text { years }\end{array}$ \\
\hline \multicolumn{2}{l}{$\boldsymbol{P}$ Value } \\
\hline NAWM vs GAD \\
RD \\
AD & .11 \\
FA & $<.001^{\mathrm{a}}$ \\
MD & $.004^{\mathrm{a}}$ \\
NAWM vs T2 lesions & $<.001^{\mathrm{a}}$ \\
RD & \\
AD & .15 \\
FA & $.002^{\mathrm{a}}$ \\
MD & .09 \\
BH vs NBH & .037 \\
RD & \\
AD & .36 \\
FA & .39 \\
MD & $.01^{\mathrm{a}}$ \\
\hline a $<.05$ & .07 \\
\hline
\end{tabular}

outside demyelination are occurring in lesional tissue that can alter $\mathrm{AD}$ but not $\mathrm{RD}$. The absence of changes in $\mathrm{RD}$ may represent the abrogation of demyelination induced by natalizumab and may explain differences with prior studies. ${ }^{31}$ The exact changes that drive the change in $\mathrm{AD}$ in lesional tissue are not clearly understood and will require further study, including an analysis of the different enhancement patterns within the gadolinium-enhancing lesions and pathologic correlation with DTI measures.

Similar to what was found in GAD tissue, a progressive increase in $\mathrm{AD}$ was observed during the 4-year study period in $\mathrm{T} 2$ lesions. This finding is of unclear significance, but similar changes have been previously reported as described above. The lack of any inflammatory-driven changes in these lesions along with the similar changes in $\mathrm{GAD}$ tissue suggests that the increase in $\mathrm{AD}$ is a real phenomenon and not a spurious result. The pathologic significance of this change is more difficult to determine. The correlation of $\mathrm{AD}$ with axonal integrity may be different in brain and optic nerve tissues, ${ }^{5}$ where fibers are more-or-less homogeneous in direction. Conversely, brain lesions may contain various different fibers, and an increase in $\mathrm{AD}$ may be due to selective loss of certain fibers, resulting in counterintuitive changes in DTI measures. $^{32}$
Our study also showed no significant difference in the evolution of RD or $\mathrm{AD}$ in $\mathrm{BH}$ and $\mathrm{NBH}$. Regarding $\mathrm{AD}$, it appears that the overall progressive increase in $\mathrm{T} 2$ lesions was likely determined by changes in $\mathrm{BH}$, and this possibility supports a biologic gradient among NAWM, NBH, and finally $\mathrm{BH}$. While changes were not significant, RD progressively increased in $\mathrm{BH}$ and decreased in $\mathrm{NBH}$; these findings suggest ongoing demyelination in $\mathrm{BH}$ and possible remyelination in NBH lesions. Remyelination is a well-described phenomenon in NBH and has been demonstrated with magnetization transfer ratio imaging previously. ${ }^{33,34}$

Our study was limited due to the absence of a control arm treated with something other than natalizumab. We aimed to study MS in a population with little inflammatory disease activity to minimize the effects of ongoing tissue inflammation on DTI measures. Our study was also limited by patients who dropped out of the study. However, it is likely that these drop-outs were patients who did not tolerate natalizumab or who stayed on the medication for only a short time, thus limiting the overall effect on the study.

An additional area of concern is the difficulty in delineating specific lesional tissue with time. Changes in the tissue architecture with time related to gliosis, resolution of edema, and brain atrophy complicate following lesions longitudinally. We used the T2 ROIs at baseline as a guide to follow the extent of the lesion on follow-up scans, but this method did not take into account areas where brain tissue remyelinates and lesions essentially resolve. This limitation is implicit in any study dealing with dynamic tissue changes. The stability of DTI measures in the first 3 time points from chronic lesion tissue and NAWM along with significant variability in GAD tissue demonstrates that DTI measures are quite sensitive to inflammatory changes. NAWM and chronic lesion measures showed good reliability during short imaging intervals ( 1 month).

A change to the b-value in the DTI sequence was required at month 12 due to vibration-related artifacts. ROI placement avoided regions affected by the vibration artifacts. Noise floor effects can result in systematic bias among measurements taken at different b-values. With a sufficiently low signal-to-noise ratio and in regions of high anisotropy, a reduction in b-value can result in an artifactual increase in diffusivity. ${ }^{35}$ However, if the effects were substantial, we would expect an increase in diffusivity in all tissue types. Decreases in diffusivity values in normal-appearing white matter and lesional tissue, while not statistically significant, suggest that the impact of bias with the change in b-value did not have a meaningful impact on our data.

The use of DTI in clinical trials has significant promise; however, the DTI outcomes to be used should be tailored depending on the therapeutic mechanism of action and MS disease type. The selection of both the DTI metrics and the tissue from which these metrics are obtained is of importance when considering outcomes for clinical trials. For trials of agents that promote remyelination, 
$\mathrm{RD}$ is a natural choice because it is thought to be a marker of myelin content. In NAWM, RD shows a tendency to increase with time. Although in our study, this increase was not statistically significant, therapies that promote remyelination may show a progressive decrease in RD. The study of RD in NAWM is advantageous because the cellular architecture is preserved and there is no confounding inflammatory activity, making the interpretation of DTI measures more straightforward. These advantages make RD within NAWM a good potential outcome for primary neuroprotection.

Although AD has been purported as a measure of axonal integrity, our results suggest that lesional AD is not likely correlated to axonal content because $\mathrm{AD}$ was not significantly different in $\mathrm{BH}$ and $\mathrm{NBH}$. $\mathrm{AD}$ may provide a sensitive measure of ongoing disease processes in lesional tissue; however, the pathologic significance of this new finding remains unclear and will have to be studied in the future. The summary measures FA and MD are difficult to interpret as stand-alone measures, so they are less attractive as clinical trial outcomes. FA appears to be a good marker of acute lesion formation; however, the longitudinal evolution of FA did not show statistically significant changes in NAWM and only marginal changes in lesional tissue. In summary, our data suggest that DTI holds promise in trials that promote remyelination and tissue repair within lesions and to a lesser extent in NAWM.

\section{CONCLUSIONS}

Lesional tissue demonstrated higher values of RD and lower values of AD compared with NAWM, likely representing demyelination with a component of axon loss. No statistically significant changes were observed with time in NAWM. A progressive increase in $\mathrm{AD}$ was also observed in GAD tissues and chronic $\mathrm{T} 2$ lesions; however, the significance of this change remains unclear from a pathologic standpoint. Our findings suggest that AD from lesional tissue may be a more sensitive metric than RD from lesions or DTI measures from NAWM. The description of AD in lesional tissue as a surrogate of axon content in MS should be revisited, given its poor ability to differentiate $\mathrm{BH}$ and $\mathrm{NBH}$.

\section{ACKNOWLEDGMENTS}

We acknowledge the assistance of our research support staff, radiology technicians, and information technology staff at the Mellen Center.

Disclosures: Daniel Ontaneda—RELATED: Grants/Grants Pending: Dr Ontaneda is supported by a National Institutes of Health (Clinical and Translational Science Collaborative of Cleveland, KL2TR000440) KL2 Award and a National Multiple Sclerosis Clinical Fellowship Award (FP 1769-A-1); UNRELATED: Consultancy: Dr Ontaneda has received consulting fees from Acorda Therapeutics, Alkermes, Biogen Idec, Genzyme, Genentech, Mallinckrodt, and Novartis; OTHER: research support from Novartis and Genzyme. Ken Sakaie-UNRELATED: Grants/Grants Pending: National Institutes of Health, ${ }^{*}$ National Multiple Sclerosis Society, ${ }^{*}$ Department of Defense, ${ }^{*}$ American Heart Association, ${ }^{*}$ the Chiari and Syringomyelia Foundation, ${ }^{*}$ Novartis, ${ }^{*}$ Genzyme, ${ }^{*}$ Biogen. * Jian Lin—RELATED: Grant: National Multiple Sclerosis Society*; UNRELATED: Grants/Grants Pending: Novartis.* Mark J. Lowe-UNRELATED: Consultancy: Siemens. Michael D. Phillips-UNRELATED: Payment for Lectures (including service on Speakers Bureaus): Siemens, Comments: honorarium for speaking. Robert J. Fox—RELATED: Grant: National Multiple Sclerosis Society (RG3546)*; UNRELATED: Board Membership: MedDay, Comments: Scientific Advisory Board; Consultancy: Avanir Pharmaceuticals, Allozyne, Biogen Idec, Novartis, Questcor Pharma- ceuticals, Teva Neuroscience; Research Support: Novartis. *Money paid to the institution.

\section{REFERENCES}

1. Lassmann H. Models of multiple sclerosis: new insights into pathophysiology and repair. Curr Opin Neurol 2008;21:242-47 CrossRef Medline

2. Ontaneda D, Fox RJ, Chataway J. Clinical trials in progressive multiple sclerosis: lessons learned and future perspectives. Lancet Neurol 2015;14:208-23 CrossRef Medline

3. Fox RJ. Picturing multiple sclerosis: conventional and diffusion tensor imaging. Semin Neurol 2008;28:453-66 CrossRef Medline

4. Beaulieu C, Allen PS. Determinants of anisotropic water diffusion in nerves. Magn Reson Med 1994;31:394-400 CrossRef Medline

5. Song SK, Sun SW, Ju WK, et al. Diffusion tensor imaging detects and differentiates axon and myelin degeneration in mouse optic nerve after retinal ischemia. Neuroimage 2003;20:1714-22 CrossRef Medline

6. Song SK, Sun SW, Ramsbottom MJ, et al. Dysmyelination revealed through MRI as increased radial (but unchanged axial) diffusion of water. Neuroimage 2002;17:1429-36 CrossRef Medline

7. Budde MD, Kim JH, Liang HF, et al. Toward accurate diagnosis of white matter pathology using diffusion tensor imaging. Magn Reson Med 2007;57:688-95 CrossRef Medline

8. Harrison DM, Caffo BS, Shiee N, et al. Longitudinal changes in diffusion tensor-based quantitative MRI in multiple sclerosis. Neurology 2011;76:179-86 CrossRef Medline

9. Goodkin DE, Rooney WD, Sloan R, et al. A serial study of new MS lesions and the white matter from which they arise. Neurology 1998; 51:1689-97 CrossRef Medline

10. Werring DJ, Brassat D, Droogan AG, et al. The pathogenesis of lesions and normal-appearing white matter changes in multiple sclerosis: a serial diffusion MRI study. Brain 2000;123(pt 8):1667-76 CrossRef Medline

11. Naismith RT, Xu J, Tutlam NT, et al. Increased diffusivity in acute multiple sclerosis lesions predicts risk of black hole. Neurology 2010;74:1694-701 CrossRef Medline

12. Rocca MA, Cercignani M, Iannucci G, et al. Weekly diffusionweighted imaging of normal-appearing white matter in MS. Neurology 2000;55:882-84 CrossRef Medline

13. Filippi M, Iannucci G, Cercignani M, et al. A quantitative study of water diffusion in multiple sclerosis lesions and normal-appearing white matter using echo-planar imaging. Arch Neurol 2000;57: 1017-21 CrossRef Medline

14. Ransohoff RM. Natalizumab for multiple sclerosis. $N$ Engl J Med 2007;356:2622-29 CrossRef Medline

15. Tuch DS, Reese TG, Wiegell MR, et al. High angular resolution diffusion imaging reveals intravoxel white matter fiber heterogeneity. Magn Reson Med 2002;48:577-82 CrossRef Medline

16. Landman BA, Farrell JA, Jones CK, et al. Effects of diffusion weighting schemes on the reproducibility of DTI-derived fractional anisotropy, mean diffusivity, and principal eigenvector measurements at 1.5T. Neuroimage 2007;36:1123-38 CrossRef Medline

17. Fox RJ, Cronin T, Lin J, et al. Measuring myelin repair and axonal loss with diffusion tensor imaging. AJNR Am J Neuroradiol 2011;32: 85-91 CrossRef Medline

18. Polman CH, Reingold SC, Edan G, et al. Diagnostic criteria for multiple sclerosis: 2005 revisions to the "McDonald criteria." Ann Neurol 2005;58:840-46 CrossRef Medline

19. Hiltunen J, Hari R, Jousmäki V, et al. Quantification of mechanical vibration during diffusion tensor imaging at 3 T. Neuroimage 2006; 32:93-103 CrossRef Medline

20. Brex PA, Parker GJ, Leary SM, et al. Lesion heterogeneity in multiple sclerosis: a study of the relations between appearances on T1 weighted images, $\mathrm{T} 1$ relaxation times, and metabolite concentrations. J Neurol Neurosurg Psychiatry 2000;68:627-32 CrossRef Medline

21. Smith SM, Jenkinson M, Woolrich MW, et al. Advances in functional 
and structural MR image analysis and implementation as FSL. Neuroimage 2004;2(suppl 1):S208-19 Medline

22. Wang S, Wu EX, Tam CN, et al. Characterization of white matter injury in a hypoxic-ischemic neonatal rat model by diffusion tensor MRI. Stroke 2008;39:2348-53 CrossRef Medline

23. Kim JH, Loy DN, Liang HF, et al. Noninvasive diffusion tensor imaging of evolving white matter pathology in a mouse model of acute spinal cord injury. Magn Reson Med 2007;58:253-60 CrossRef Medline

24. Castriota Scanderbeg A, Tomaiuolo F, Sabatini U, et al. Demyelinating plaques in relapsing-remitting and secondary-progressive multiple sclerosis: assessment with diffusion MR imaging. AJNR Am J Neuroradiol 2000;21:862-68 Medline

25. Nusbaum AO, Lu D, Tang CY, et al. Quantitative diffusion measurements in focal multiple sclerosis lesions: correlations with appearance on TI-weighted MR images. AJR Am J Roentgenol 2000;175: 821-25 CrossRef Medline

26. Bitsch A, Kuhlmann T, Stadelmann C, et al. A longitudinal MRI study of histopathologically defined hypointense multiple sclerosis lesions. Ann Neurol 2001;49:793-96 CrossRef Medline

27. Brück W, Bitsch A, Kolenda H, et al. Inflammatory central nervous system demyelination: correlation of magnetic resonance imaging findings with lesion pathology. Ann Neurol 1997;42:783-93 CrossRef Medline

28. Rashid W, Hadjiprocopis A, Davies G, et al. Longitudinal evaluation of clinically early relapsing-remitting multiple sclerosis with diffusion tensor imaging. J Neurol 2008;255:390-97 CrossRef Medline

29. Boretius S, Escher A, Dallenga T, et al. Assessment of lesion pathology in a new animal model of MS by multiparametric MRI and DTI. Neuroimage 2012;59:2678-88 CrossRef Medline

30. Kuhlmann T, Lingfeld G, Bitsch A, et al. Acute axonal damage in multiple sclerosis is most extensive in early disease stages and decreases over time. Brain 2002;125:2202-12 CrossRef Medline

31. Moll NM, Rietsch AM, Thomas S, et al. Multiple sclerosis normalappearing white matter: pathology-imaging correlations. Ann $\mathrm{Neu}$ rol 2011;70:764-73 CrossRef Medline

32. Roosendaal SD, Geurts JJ, Vrenken H, et al. Regional DTI differences in multiple sclerosis patients. Neuroimage 2009;44:1397-403 CrossRef Medline

33. Zivadinov R, Hussein S, Bergsland N, et al. Magnetization transfer imaging of acute black holes in patients on glatiramer acetate. Front Biosci (Elite Ed) 2012;4:1496-504 Medline

34. Chen JT, Kuhlmann T, Jansen GH, et al; Canadian MS/BMT Study Group. Voxel-based analysis of the evolution of magnetization transfer ratio to quantify remyelination and demyelination with histopathological validation in a multiple sclerosis lesion. Neuroimage 2007;36:1152-58 CrossRef Medline

35. Jones DK, Basser PJ. "Squashing peanuts and smashing pumpkins": how noise distorts diffusion-weighted MR data. Magn Reson Med 2004;52:979-93 CrossRef Medline 